\title{
Court-ship, kinship and business: a study on the interaction between the formal and the informal institutions and its effect on entrepreneurship
}

\author{
Tanika Chakraborty ${ }^{1 *}$, Anirban Mukherjee ${ }^{2}$ and Sarani Saha ${ }^{1}$
}

\author{
*Correspondence: tanika@iitk.ac.in \\ ${ }^{1}$ Indian Institute of Technology, \\ Kanpur, India \\ Full list of author information is \\ available at the end of the article
}

\begin{abstract}
In this paper we theoretically and empirically examine how the interaction between the formal court system and the informal loan network affects a household's decision to start a business. We find that when the formal court system is weak, expansion of informal credit network leads to the proliferation of business. However, with a sufficiently strong court system, expansion of the credit network has a negative effect on business prospects. This result is explained by the contradictions between formal laws and norms used by informal networks.
\end{abstract}

JEL codes: $\mathrm{K} 12 ; \mathrm{L} 26 ; \mathrm{O} 17$

Keywords: Informal network; Court; Formal institution; Entrepreneurship

\section{Introduction}

Effective contract enforcement is the key to the process of economic development. A contract can be enforced by the formal legal court or by informal community courts, for instance panchayats in South Asia. In less developed societies both types of institutions co-exist, often coming in each others way. These conflicts are well documented in the context of the marriage market and common property management (Chowdhry 2004; Keremane et al. 2006; Madsen 1991; Nagraj 2010; Yadav 2009). However, till date there has not been any study that analyzes and estimates the effect of such interactions on economic decision making. In this paper we look at the effect of the interaction between the informal loan network and formal court system on the decision to run a business using both analytical and quantitative methods. We find that the informal network helps in business proliferation when the formal court system is weak. However, when the formal court system improves sufficiently, business might fall in areas with strong informal networks.

Our paper is related to a vast body of literature that studies the effect of institutions on economic development. There is a consensus among economists that better institutions encourage capital accumulation and subsequent growth (Acemoglu et al. 2001, 2002; Rajan and Zingales 1998). However, the existing empirical literature on the effectiveness of formal institutions mostly look at the institutions of property rights which prevent the

(c) 2015 Chakraborty et al.; licensee Springer. This is an Open Access article distributed under the terms of the Creative Commons Attribution License (http://creativecommons.org/licenses/by/4.0), which permits unrestricted use, distribution, and reproduction in any medium, provided the original work is properly credited. 
elites from expropriating. One exception is Acemoglu and Johnson (2003), who distinguish between the effects of property rights institutions and contracting institutions on growth. Using a cross country data set, they find that while good property rights institutions have a positive effect on growth, the effect of contracting institutions is not robust. This result is counter intuitive, and one possible reason could be that their data, which only measures the quality of formal contracting institutions, fails to account for the role of informal network based institutions, ubiquitous in many developing countries. Evidence shows that in the absence of effective formal courts of law, business often thrives under the informal institutions (Biggs and Shah 2006; McMillan and Woodruff 1999). In a related paper, Harriss-White (2010) finds that in absence of effective formal institutions, Indian SMEs are largely regulated by what she calls "social regulation." This is nothing but informal institutions working through community networks and reputation mechanisms. The caste system prevailing in India can also be seen as a grand framework of contract enforcement using the reputation mechanism (Freitas 2006). The key to the success of such reputation based mechanisms is information about one's past action (therefore reputation) flowing in the community network (Ghosh and Ray 1996; Rosenthal and Landau 1979; Kandori 1992). Many credit institutions in less developed countries, such as ROSCA in East Asia (Besley et al. 1993) and Grameen Bank in Bangladesh (Ghatak 1991), crucially depend on such information flow within communities. The use of community level information for enforcing contracts was also ubiquitous in medieval Europe (Greif et al. 1994; Greif 1993; Slivinski and Sussman 2009).

Besides the general literature on institutions and its impact on economic growth, this paper is also related to the role of networks in credit provisioning. Network membership, which is often characterized by caste or ethnicity, may work both in positive and negative ways. A number of studies found in the African context that community membership can increase the probability of getting a loan if one's own community controls the supply of loans (Biggs and Srivastava 2002; Fafchamps 2000,2003, Fisman 2003; Gajigo and Foltz 2010). On the other hand, it may decrease the probability of getting loans if the credit granting authority has any negative bias towards the credit applicants ethnicity. This result has been confirmed by various studies in the context of the United States (Blanchflower et al. 2003; Fairlie and Robb 2007).

However, most of the literature on institutions look at formal and informal institutions as separate phases of development - the informal system getting replaced by the formal ones in due course of development (La Porta and Shleifer 2014). At best, some authors have adopted a dual sector approach - making formal and informal two parallel sets of rules without interfering with one another (Straub 2005). But in reality, formal and informal institutions interact and mutually constitute each other. Evidence suggests that social capital affects formal economic behavior like financial decisions. Luigi et al. (2004) find that in Italy people are more likely to use formal checks, invest less in cash and more in stocks, have higher access to institutional credit and make less use of informal credit in areas of high social capital. The effect of social capital is stronger in areas with weaker legal enforcements. In a similar line of research, Karlan (2005) uses an experimental approach to find the effect of social capital on financial decisions. The interaction between formal institutions and informal norms also plays a role in the management of common property resources. For example, Sandner (2003) looked at the interaction between formal institutions and norms of the Kuna community in Central America for preservation of 
marine resources. He shows that erosion of norms and insufficient development of formal institutions can lead to over exploitation of marine resources.

The interaction between formal and informal institutions is particularly important in less developed countries. In these countries de facto practices are quite different from de jure rules - and these differences are often shaped by the interaction between formal and informal institutions. The only theoretical exposition of such interactions that we have come across is Dixit (2004) where he argues that the development of the formal may have a detrimental effect on the informal mechanisms. The informal system relies heavily on the reputation mechanism, where someone with a reputation of cheating does not get a job within his/her community. People using formal contracts however do not care about reputation - punishment under formal contracting is direct and enforced by a third party (fine, imprisonment). Hence one can always cheat someone using the informal contract and then find their next employment with another employer using a formal contract.

On the empirical front there has been much less research on this issue. One of the few papers related to relevance of institutions in affecting business decisions is Chemin (2012). He finds that reforms in the civil court procedure leads to lower breaches of contract, higher access to capital and building of new capacity in India. However, what Chemin finds is an average effect of more efficient courts. His research does not answer whether the effect is different for areas with different initial conditions in terms of informal institutions (such as the presence of caste panchayat). We claim that the effect of better legislation on business decisions will critically depend on these initial conditions. Another closely related paper is Klapper et al. (2006). Their study, based on 34 Eastern and Western European countries, find that higher requirements to comply with formal bureaucratic regulation prevents new businesses from entering the industry by increasing entry cost.

The main contention of our paper is that formal and informal institutions might come in the way of each other, producing undesired results in places where traditional, community based dispute resolving systems are widespread. We define a business in terms of a contract where a contractor agrees to supply certain inputs to an entrepreneur. The quality of the input cannot be verified beforehand or by any third party, creating a possible moral hazard problem. The only way to punish a cheater contractor is to fire him and deny him any future employment opportunity. Hence, we have a structure similar to Shapiro and Stiglitz (1984) and Greif (1993), where the only way to prevent cheating is to pay the cheater contractor an honesty-inducing price for his input so that he finds that cheating pays off is less than the honesty pay-off.

The entrepreneurs can come from a traditional producer community or someone coming from outside the community. The latter group can only enter the market if the formal contracting institutions are of sufficiently good quality. For entrepreneurs belonging to the traditional community, the community norm requires them to boycott a contractor who cheated any community member. This makes the cost of cheating someone very high for the contractor, depressing the honesty inducing price of his input supplies.

We argue that in the presence of an effective formal system, the capacity to punish declines in the informal system. This is precisely because a strong formal system allows entrepreneurs from outside the community to enter the market who do not abide by the community norm of not hiring a past cheater. This makes it easy for a cheater contractor (who cheated a community member in the past) to find employment with an entrepreneur who does not belong to the community. This increases the honesty 
inducing price for the input, pushing the entrepreneurs with small capital stock out of the market.

Our theoretical model suggests that in areas with strong networks, an honesty inducing input price is low, accommodating small entrepreneurs in the system. But as formal systems improve (and consequently the input price rises), these areas are the worst hit as facing the rising input prices, the entrepreneurs are forced to quit the market.

We use the India Human Development Survey (IHDS) 2004-2005 to test our theoretical predictions. In accordance with the theoretical predictions, our empirical evidence suggests that business is affected by the interplay of formal institutions and informal norms. Specifically, when formal institutions are strong enough, we find that the probability of doing business is lower in the presence of a large informal network. Given the cross-sectional nature of the data, we should be careful in interpreting our results as causal.

However, this inference does not suggest the preservation of the informal institutions by limiting the power of the formal courts. It rather emphasizes the possibility of jeopardizing the expansion of business by imposing a rapid expansion of the formal contracting system. There is no point in denying that improvement in formal contracting enhances efficiency and social mobility by allowing contractors without any family/community connection to enter the market. However, the preexistence of a strong informal institutional framework, captured by large community networks, makes the rapid institutional switch socially costly as it may exclude people from participating in the market. Most importantly, the exclusion comes from the high cost of accessing the formal institutions. Given the efficiency property of formal institutions, the most logical implication of our research is to reduce the cost of formal contracting.

The rest of the paper is organized as follows. Section 2 presents the analytical model, Section 3 outlines the empirical framework, Section 4 summarizes the data used to test the implications of our model, Section 5 reports the empirical findings and, finally, Section 6 concludes.

\section{Model}

\subsection{Agents: contractors and entrepreneurs}

There is a pool of potential entrepreneurs who produce a good G. For producing the good G, they need an input $\mathrm{X}$, which is supplied by a set of contractors who come from a traditional $\mathrm{X}$ producing community $\mathrm{C}$. The entrepreneurs however may come from both the traditional community $(\mathrm{C})$ and outside community $(\mathrm{NC})$. The production of the input requires high skill, but only a fraction of the community $\mathrm{C}$ has the skill - we call them High type contractors. The rest of the contractors, who we call Low type, do not have the necessary skill to supply the input. Therefore, if a low type is chosen, the entrepreneur makes zero profit. Whether a contractor is High type is common knowledge within the $\mathrm{C}$ community but not outside. So when a contractor from $\mathrm{C}$ community asks for work, a typical NC entrepreneur cannot tell whether the contractor has the appropriate skill. This however is common knowledge for a $\mathrm{C}$ entrepreneur For an $\mathrm{NC}$ entrepreneur, the first problem is that of adverse selection - to be able to distinguish between the High and the Low type.

However, there is a second level problem as well - the problem of moral hazard. Even after a High type contractor is selected, he may supply bad quality input as it saves effort for the contractor. Note that using a bad quality input for producing $G$ is better than 
hiring a Low type contractor. A Low type contractor is a fraud who does not have the skill to produce the input even of bad quality. Hence, from an entrepreneur's perspective, a High type supplying bad quality input yields a better outcome than hiring a Low type contractor who cannot supply any input. We write the condition as follows:

$$
0<\kappa<\pi^{B}<\pi^{G},
$$

where $\kappa$ is the reservation income of the entrepreneur. $\pi^{j}$ is his income by hiring the high type contractor, where the contractor supplies quality $j$ input $(j=B, G)$. If the entrepreneur hires the Low type contractor, he gets 0 profit, which is less than his reservation pay-off. Hence, while choosing a contractor faces two types of problems, the first one is a typical problem of adverse selection, and the second one is of moral hazard.

Before proceeding further let us discuss why both the moral hazard and adverse selection problems are necessary for the formulation of our model.

The moral hazard and the adverse selection problems bring out the role that two types of institutions - formal and informal - play. Let us first take the case of the moral hazard problem where a contractor can shirk. The only punishment for cheating is not hiring a cheater again. For entrepreneurs belonging to the entrepreneurial caste, if one entrepreneur is cheated, all entrepreneurs belonging to the caste boycott the cheater contractor. This makes the punishment cost of cheating a caste entrepreneur more than cheating a non-caste member. The informal institutions in this case take the form of information flow within the community. This information advantage allows the caste entrepreneurs to impose the punishment on a cheating contractor. This is not possible in the case of non-caste entrepreneurs due to the lack of credible information. Instead, the non-caste members who cannot go to informal institutions solve the moral hazard problem simply by paying a higher honesty-inducing wage than their caste member counterpart. Note that this analysis does not require modeling of formal institutions.

The adverse selection problem, on the other hand, arises in the model because, ex-ante, it is not possible to distinguish between the Low and the High type. Here comes the role of formal institutions. The formal institutions of contract enforcement are essentially third party enforcement (court, police etc). They solve this problem by punishing a Low type contractor who poses as the High type contractor. The higher is the quality of the formal institutions, the higher is the probability of catching and punishing a Low type mimicking a High type. Therefore, the quality of formal institutions enters our analysis through the channel of the adverse selection problem, making the adverse selection problem crucial to our theory. Both the moral hazard and adverse selection problems are important in our analysis because they are solved by the informal and formal institutions respectively.

The entrepreneurs can be characterized in two dimensions: community identity and endowment. An entrepreneur $i$ is endowed with business skill, or capital, $\theta_{i}$, and the endowment is distributed according to the distribution $\phi$. An entrepreneur $i$ 's output $y_{i}$ is positively related to his endowment. There is another dimension of any entrepreneur - either he belongs to a traditional business community $(C)$ or does not belong to that community (NC). However, the distributions for $\theta$ are the same for $\mathrm{C}$ and $\mathrm{NC}$ type entrepreneurs. The main difference between $\mathrm{C}$ and $\mathrm{NC}$ types is in terms of accessing informal institutions. Only $\mathrm{C}$ type entrepreneurs can access the informal network for adjudicating any dispute with the contractors. However, both $\mathrm{C}$ and NC type entrepreneurs can access the formal court. Note that the quality of an input (good or bad) 
cannot be verified by the court. Hence, the court is only useful if a Low type contractor misrepresented himself as a High type and took money for supplying the input.

The entrepreneur faces two levels of problems. Finding a High type is the first level of the problem. In the second level, the entrepreneur has to ensure that the High type is not behaving opportunistically - i.e., not supplying bad input after being hired.

\subsection{Institutions}

Let us now elaborate the role of institutions in solving the problems faced by the entrepreneurs. There are two types of contracting institutions available in the economy. One is formal courts characterized by third party enforcement and the second is informal networks characterized by reputation based mechanisms. In what follows, we discuss the different roles played by the formal versus informal institutions in solving the problem of asymmetric information faced by the entrepreneurs.

\subsection{Adverse selection problem: the role of court}

We have already mentioned that there are two types of problems that an entrepreneur faces: Low type posing as High type, and after recruitment, high type supplying bad quality input. From the entrepreneur's point of view, a low type contractor (who can only supply zero input) is worse than hiring a high type who supplies bad quality. There are two ways of catching and punishing a Low type.

The informal network of $\mathrm{C}$ members possesses the information regarding its member's skillfulness, i.e., everybody in the community knows which member in the community does not have the necessary training to produce X. Hence, no Low type contractor is hired by a $\mathrm{C}$ type entrepreneur. In other words, belonging to the community network solves the problem of adverse selection for a $\mathrm{C}$ entrepreneur. But NC entrepreneurs cannot access this information about the true type of the contractor, ex-ante. Instead, the NC entrepreneurs can sign a formal contract with a potential contractor, and if he turns out to be the Low type, they can file a lawsuit against the Low type posing as High and get the Low type punished with probability $\sigma$, where, $\sigma$ is the quality of the formal court. Hence, with a sufficiently strong formal court, Low type community members will not pose as a High type member. In general, mimicking the High type is not worthwhile for the Low type if

$$
\sigma(P-M)+(1-\sigma)(P)<0,
$$

where $P$ is the price that the low type gets by posing as the High type, and $\mathrm{M}$ is the penalty he pays if he gets caught. The reservation pay-off of the Low type is 0 . The condition tells us that there will be no Low type posing as High type if

$$
\sigma>\frac{P}{M}=\sigma^{*}
$$

For $\sigma<\sigma^{*}$ the quality of formal institutions is so bad that Low types can mimic High types and get away with it. This makes the NC type entrepreneurs find that it is not worthwhile to join the market. For low enough sigma, all Low types mimic as high types, and given that $C$ type entrepreneurs already know who is Low type, there is a very high probability that NC type entrepreneurs are matched with Low type. This leads to our first theorem: 
Theorem 2.1. For a sufficiently high quality of formal institutions $\left(\sigma^{*}\right)$, Low types do not find it worthwhile to mimic the High type, and as a result, NC entrepreneurs enter the market.

\subsection{The moral hazard problem}

Unlike adverse selection, the moral hazard problem however cannot be solved by any third party as the quality of the input is not verifiable by the third party. Only the entrepreneur can find out the quality of the input, and the punishment she can inflict is not hiring a cheater contractor for subsequent periods. The monetary value of the punishment can be measured by a wage that a contractor loses if he is fired. We follow the efficiency wage theory framework proposed by Shapiro and Stiglitz (1984) and Greif (1993) for analyzing the solution to the moral hazard problem.

We start with the case where $\left(\sigma<\sigma^{*}\right)$, and only C type entrepreneurs operate. C entrepreneurs solve the adverse selection problem of selecting the High type through the information network. Hence, they face the moral hazard problem only - the problem of ensuring that High type supplies good quality input. The entrepreneur can solve the problem by offering a payment to the contractor so that the cheating pay-off is less than the honesty pay-off. This section is modeled after Greif (1993).

The contractor supplies one unit of the input to the entrepreneur and gets a payment $\rho$. If he supplies bad quality input, he saves some cost $\eta$ but at the end of the period gets fired. However, there is an exogenous probability of terminating the contract given by $q$. In that case, if the contractor is honest, he is hired again. For characterizing the honesty inducing equilibrium, we define the following expressions:

The pay-off for an honest agent is given by

$$
V_{h}=\rho+\beta(1-q) V_{h}+q V_{h}^{u}
$$

This shows that the lifetime payoff of an honest contractor can be divided in to current and future pay-offs. In the current period an honest agent gets factor payment $\rho$. In the next period, however, she might get fired for an exogenous reason with probability $q$ and continue to get $V_{h}^{u}$ - the lifetime pay off of an honest unemployed agent. On the other hand, the agent may stay in the job with probability $1-q$ and continue to earn an honest employed agent's pay-off $-V_{h}$. The future pay offs are discounted by the discount rate $\beta$.

By cheating, an agent gets a one time pay-off $\eta$ in the current period. However, this one time payment comes at the cost of losing his job at the end of the current period. From the next period onwards he gets the pay-off of an unemployed cheater. An unemployed cheater can be rehired with probability $p_{c}$ in the next period and get $V_{h}$. With probability $\left(1-p_{c}\right)$ a cheater is not re-hired, and he gets reservation wage $(\bar{\omega})$. The pay-off for an unemployed cheater, $V_{c}^{u}$, is summarized by the following equation:

$$
V_{c}^{u}=\beta p_{c} V_{h}+\beta\left(1-p_{c}\right)\left(\bar{\omega}+V_{c}^{u}\right)
$$

An honest agent can also lose her job for exogenous reasons. However, she may be rehired with probability $p_{h}$ in the next period and get $V_{h}$. On the other hand, with probability $\left(1-p_{h}\right)$ she may remain unemployed and get $\left(\bar{\omega}+V_{h}^{u}\right)$ - reservation pay-off plus life time utility of an honest unemployed agent.

$$
V_{h}^{u}=\beta p_{h} V_{h}+\beta\left(1-p_{h}\right)\left(\bar{\omega}+V_{h}^{u}\right)
$$


The payment to a contractor $(\rho)$ that prevents her from cheating must satisfy the condition

$$
V_{h} \geq \eta+V_{c}^{u}
$$

It is easy to understand that no entrepreneur has any incentive to pay a $\rho$ more than the minimum honesty-inducing payment.

Theorem 2.2. A contractor's honesty inducing payment is rising in the probability of rehiring a cheater agent.

We provide the formal proof in the appendix. But the intuition of this theorem is quite straight forward. The only punishment an entrepreneur can inflict is firing the agent, which involves the monetary cost of the forgone payment. If the cheater agents can easily be rehired, the cost of losing the current job is low. In that case the input price (that he misses because of getting fired) needs to be big enough to prevent one from cheating. So we have $\rho^{*}=\rho\left(p_{c}\right), \rho^{\prime}>0$. We assume that community members will not appoint a contractor who has cheated another community member, i.e., in the environment where all the entrepreneurs are type $\mathrm{C}$, we get $p_{c}=0$. This is possible due to the flow of information within the community of a $\mathrm{C}$ type entrepreneur. However, an NC type contractor cannot access any such information. Hence, she cannot distinguish between an agent who cheated in the past and the one who did not. For her $p_{c}=p_{h}>0$, this leads to the next corollary:

Corollary 2.3. The honesty inducing payment for the contractors hired by NC entrepreneurs is higher than that for the ones hired by the $C$ entrepreneurs.

\subsection{The interaction effect}

First we analyze how the improvements in the formal court system affects the $C$ type entrepreneurs. The improvements in the formal court system do not directly affect $\mathrm{C}$ type entrepreneurs. It affects the $\mathrm{C}$ type by facilitating the entry of the NC type. NC type entrepreneurs can only enter the market if the formal institutions are good enough to solve the adverse selection problem. Hence, a good court allows the NC entrepreneurs to enter the market. Once in the market, the $\mathrm{NC}$ entrepreneurs solve the moral hazard problem the same way the $C$ entrepreneurs solve the problem, i.e., paying the honestyinducing price. But the entry of NC entrepreneurs will have an indirect impact on the $\mathrm{C}$ entrepreneurs as the equilibrium price for the input will go up, reducing the profit margin of the existing $C$ entrepreneurs. This determines the number of $C$ entrepreneurs. Who are the $C$ entrepreneurs running businesses? The entrepreneurs with endowment $\theta_{i}$ will be in business such that

$$
\pi_{i}\left(\theta_{i}\right) \geq \rho^{*},
$$

where $\rho^{*}$ is the equilibrium price for the input. Solving (8) for equality, we get the lowest endowment entrepreneur that can be in the business $\widetilde{\theta}=\theta\left(\rho^{*}\right)$, where $\tilde{\theta}$ is rising in $\rho^{*}$. From this we get our next proposition 
Theorem 2.4. The cut-off endowment level of the entrepreneurs is a function of the input price, and the cut-off goes up as the input price goes up

If the equilibrium input price $\left(\rho^{*}\right)$ goes up, only the entrepreneurs with sufficiently high endowment can stay in the market. As the input price goes up following the entry of the NC type entrepreneurs, the cut-off endowment level goes up. Let us now look at the volume of business following the entry of the NC entrepreneurs. Entry of the NC entrepreneurs increases the number of $\mathrm{NC}$ business, but it decreases the number of the $\mathrm{C}$ entrepreneurs as the cut-off endowment level gets revised upwards. Hence, theoretically, the net effect is ambiguous, making the empirical investigation important.

Suppose the number of possible community entrepreneurs is $M_{c}$. In period 0 we do not have any $\mathrm{NC}$ entrepreneur in the market. So the number of businesses is equal to the probability that a potential $C$ entrepreneur will start a business times $M_{C}$. Suppose in period 0 the cut off endowment level was $\theta_{0}$. Hence the total number of businesses is given by

$$
B_{0}=M_{C} \times\left(1-\Phi\left(\theta_{0}\right)\right)
$$

In period $1, \mathrm{NC}$ entrepreneurs enter, and as a result, input price goes up, moving the cutoff endowment level to $\theta_{1}>\theta_{0}$ for both $\mathrm{C}$ and $\mathrm{NC}$ entrepreneurs as they both face the same input price. Hence, while new entrants (NC entrepreneurs) add to the volume of business, the quitting community entrepreneurs reduce it, making the net effect ambiguous. Assume that the pool of potential NC entrepreneurs is $M_{N}$. The volume of NC businesses is given by

$$
B_{1}^{N}=M_{N} \times\left(1-\Phi\left(\theta_{1}\right)\right)
$$

The number of community businesses in period 1 is given by

$$
B_{1}^{C}=M_{C} \times\left(1-\Phi\left(\theta_{1}\right)\right)
$$

Hence, total business in period 1 is given by

$$
B_{1}=M_{N} \times\left(1-\Phi\left(\theta_{1}\right)\right)+M_{C} \times\left(1-\Phi\left(\theta_{1}\right)\right)
$$

The change in business is given by

$$
B_{1}-B_{0}=M_{N}\left(1-\Phi\left(\theta_{1}\right)\right)-M_{C}\left(\Phi\left(\theta_{1}\right)-\Phi\left(\theta_{0}\right)\right)
$$

From this we get $B_{0} \lesseqgtr B_{1}$ according to

$$
\frac{M_{N}}{M_{C}} \gtreqless \frac{\left(\Phi\left(\theta_{1}\right)-\Phi\left(\theta_{0}\right)\right.}{\left(1-\Phi\left(\theta_{1}\right)\right)}
$$

Theoretically we do not have any clear cut answer as to whether entry of NC entrepreneurs will lead to an increase or decrease in the number of businesses. This depends on the relative size of the pool of $\mathrm{C}$ and NC entrepreneurs and the shape of the endowment distribution. The larger is the value of $M_{C}$ compared to $M_{N}$, the more likely it is that with the improvement in the formal institutions (and consequently entry of the NC entrepreneurs), total number of businesses will fall. This will happen when the new entry will not be sufficient to cover for the exit of the community entrepreneurs. In other words, the entrants come from the upper tail of the endowment distribution, while the quitters come from the lower tail. Hence, total business will shrink if the lower tail is denser than the upper tail. This should be the case for a less developed country 
characterized by inequality, where the number of people belonging to the upper wealth percentile is less than that in the lower percentile.

Next we review the interaction effect between the formal and the informal institutions and its effect on the volume of business. In the previous sections we have assumed that there is one homogeneous community network where the probability of rehiring a cheater is zero. We now extend this set up by introducing heterogeneity in terms of community network. We assume that there are $n$ districts, and each district $j$ is characterized by network size $v_{j}$. We further assume that the probability of rehiring a cheater is a falling function of the network size

$$
p_{c}^{j}=g\left(v_{j}\right)
$$

where $g^{\prime}<0$. This assumption implies that in a district characterized by big network, a large number of people know about one's cheating history, and the cheater finds it difficult to get a job. Let us now elaborate how the improvements in the formal court system affects districts with different degrees of networks differently.

In other words, we examine the role of interaction between the existing informal network mechanism and the formal institutions in determining the volume of business. In period 0 , the larger the network, lower is the probability for a cheater contractor to be rehired, and lower is the input price. Hence, in a district characterized by a larger network, the cutoff endowment level for the $\mathrm{C}$ entrepreneurs is lower than that in a district with a smaller network. This means

$$
\theta_{0}=\theta(v)
$$

where $v$ represents the size of the network and $\theta^{\prime}(v)<0$. This means that the value of $\theta_{0}$ is low in high network districts. Given that $\theta_{1}$ is determined by the cut-off level of the $\mathrm{NC}$ entrepreneurs, which has nothing to do with the existing network size, the expression $\left(\Phi\left(\theta_{1}\right)-\Phi\left(\theta_{0}\right)\right)$ is rising in the network size. Since the size of the quitting businesses is rising in $\left(\Phi\left(\theta_{1}\right)-\Phi\left(\theta_{0}\right)\right.$, we get the following theorem

Theorem 2.5. If formal institutions improve, sufficiently allowing the NC entrepreneurs to set up business, the reduction in the community businesses will be higher in high network districts than that in the low network districts. If the negative impact of the quitting $C$ entrepreneurs is strong enough, this will lead to greater reduction in the total volume of business in the districts with higher networks.

We next turn to the empirical section to test the implications of our model using data from India.

\section{Empirical specification}

Empirically, a way to test the theoretical predictions would be to estimate a regression of the probability of doing business on the the interaction between formal and informal institutions using panel data. A panel setting would enable us to estimate the effect of introducing formal institutions in an economy with pre-existing informal institutions. However, in the absence of any longitudinal information, we only provide suggestive evidence on our theoretical predictions. Specifically, we compare districts with varying 
degrees of informal and formal institutions using cross sectional data. In particular, we estimate the following specification:

$$
P(S E)_{i d}=\beta_{0}+\beta_{1} I N_{d} * F C_{d}+\beta_{2} I N_{d}+\beta_{3} F C_{d}+X_{i d}+\epsilon_{i d},
$$

where $P(S E)_{i d}$ reflects the probability with which a household $i$ in district $d$ chooses to be self-employed over being wage employed. $I N_{d}$ is a proxy for the quality of informal institutions in district $d . F C_{d}$ is a proxy for the quality of formal institutions in district $d$. The interaction between $I N_{d}$ and $F C_{d}$ is our main variable of interest. According to theoretical predictions of our model, a positive $\beta_{2}$ would imply that a higher proportion of households choose to do business when the informal network is large, which thereby helps to facilitate information flow within the network. Additionally, $\beta_{1}$ captures the impact of formal institutions on the relationship between informal institutions and self-employment. Specifically, a negative $\beta_{1}$ would imply that when the quality of formal institutions increasess businesses would exit from areas with a greater prevalence of informal institutions. Similarly, $\beta_{3}$ captures the independent effect of the quality of formal institutions on probability of self employment. A positive $\beta_{3}$ implies that as the quality of formal institution improves, businesses would flourish as it enables some new entrepreneurs to enter the market.

Note however that informal and formal institutions might evolve endogenously at the district level. One way to deal with this could be to use historical data to capture the introduction of the formal court system. ${ }^{1}$ However, we cannot adopt this approach due to the paucity of such data. Instead, we try to control for a range of household and district level controls captured in $X_{i d}$. Specifically, we include religion, caste, education, amount of loan taken, any caste-group membership at the household level and availability of formal loans at the district level.

\section{Data}

We use data from the India Human Development Survey (IHDS) for this study. The IHDS is a nationally representative survey of 41,554 households interviewed in 2004 and 2005 (Desai et al. 2009). Surveyed households are distributed across 382 of India's 602 districts. Our study covers households which are either self-employed, wage employed or unemployed. This leads to a sample size of 34,521 households across 373 districts in our study. For our dependent variable we use the information on employment status of different members of a household to create a household level variable of self-employment status. We define a household to be self employed if at least one member in the household owns a business in the non-agricultural sector. A household is defined to be wage-employed if at least one member is wage-employed, and no one is self-employed. A household is defined to be unemployed if no one in the household is employed. ${ }^{2}$

Our main variables of interest are informal and formal institutional quality. In equation 17, we proxy informal institutions, $I N_{d}$, by the fraction of households in a district $d$ that takes loans from informal sources, viz., friends, relatives and community credit groups. ${ }^{3}$ In general, an informal loan network not only captures the extent of loans available in a district, but it also reflects the close association between members of the network. A larger size of the informal network facilitates flow of information within the network and helps in enforcing the reputation mechanism.

The quality of formal institutions is captured by the perceived quality of formal courts of law. We measure $F C_{d}$ as the fraction of households in a district $d$ which perceives the 
judiciary to be strong. ${ }^{4}$ Specifically, the survey asks households to rank different institutions on a scale of one to three, where three signifies the least confidence in a particular institution, and one signifies the highest confidence. We consider the perceived court quality to be strong when a household's ranking of court efficiency is one.

Table 1 provides the summary of our estimation sample. About $23 \%$ of our full sample is self employed. However, when we disaggregate by sector, we find a much higher prevalence of self employment in the urban sector - about $29 \%$ of the sample is self-employed in urban as opposed to $19 \%$ in the rural sector. This has implications for the importance of the relationship between self-employment and institutional quality, which we revisit in Section 5.1. When we look at the prevalence of informal networks, we find that about $12 \%$ of the full sample has borrowed from informal sources. Moreover, the extent of informality is not very different between urban and rural sectors. With respect to the quality of formal courts, $53 \%$ of our full sample perceive the court to be efficient. Once again, the difference in perception is small between urban and rural sectors. The availability of formal loans is higher in rural areas, possibly reflecting the higher prevalence of government rural banks providing agricultural loans. However, as expected, the average size of loans is much higher in urban regions. Table 1 additionally reports the means for the other control variables that we use in our empirical specification.

Table 1 Summary

\begin{tabular}{|c|c|c|c|}
\hline & All & Rural & Urban \\
\hline \multirow[t]{2}{*}{ Fraction Self Employed } & 0.232 & 0.195 & 0.289 \\
\hline & $(0.422)$ & $(0.396)$ & $(0.454)$ \\
\hline \multirow[t]{2}{*}{ Mean District Population } & 815.026 & 808.634 & 826.557 \\
\hline & $(438.6)$ & (349) & $(565)$ \\
\hline \multirow[t]{2}{*}{ Informal Network(IN) } & 0.124 & 0.131 & 0.112 \\
\hline & $(0.113)$ & $(0.111)$ & $(0.126)$ \\
\hline \multirow[t]{2}{*}{ Perceived Court Quality(FC) } & 0.533 & 0.545 & 0.512 \\
\hline & $(0.192)$ & $(0.193)$ & $(0.214)$ \\
\hline \multirow[t]{2}{*}{ Formal Loan Availability } & 0.153 & 0.166 & 0.131 \\
\hline & $(0.099)$ & $(0.103)$ & $(0.103)$ \\
\hline \multirow[t]{2}{*}{ Loan Amount } & 44381.67 & 32719.12 & 73513.91 \\
\hline & $(212311)$ & (108359) & (356614) \\
\hline \multirow[t]{2}{*}{ Size Caste Network } & 0.133 & 0.147 & 0.106 \\
\hline & $(0.194)$ & $(0.213)$ & $(0.172)$ \\
\hline \multirow[t]{2}{*}{ Hindu } & 0.807 & 0.824 & 0.776 \\
\hline & $(0.394)$ & $(0.381)$ & $(0.416)$ \\
\hline \multirow[t]{2}{*}{ Brahmin } & 0.058 & 0.041 & 0.089 \\
\hline & $(0.234)$ & $(0.198)$ & $(0.285)$ \\
\hline \multirow[t]{2}{*}{ HH Fraction literate } & 0.791 & 0.729 & 0.901 \\
\hline & $(0.407$ & $(0.444)$ & $(0.298)$ \\
\hline \multirow[t]{2}{*}{ HH Caste Association } & 0.133 & 0.148 & 0.106 \\
\hline & $(0.339)$ & $(0.355)$ & $(0.308)$ \\
\hline Observations & 41554 & 26734 & 14820 \\
\hline
\end{tabular}




\section{Results}

Table 2 reports the results from a linear estimation of equation 1 . The outcome variable reflects the probability of a household being self-employed compared to being wage employed. Column 1 includes a measure of informality at the district level $\left(I I_{d}\right)$, an indicator for strong institutions $\left(S I_{d}\right)$, and an interaction between the two. Since our variables of interest vary only at the district level, we report clustered standard errors at the district level in all specifications.

The results in column 1 indicate a nonlinear relationship between the degree of informality and self employment. The coefficient on informal networks by itself suggests that a greater extent of informality in a district predicts a higher probability of self-employment. However, this relationship depends on the strength of formal institutions. Specifically, the negative coefficient on the interaction term implies a nonlinear relationship. This can be seen from the following equation.

$$
\frac{\partial \operatorname{Pr}(S E)}{\partial I I_{d}}=-\beta_{1} S I_{d}+\beta_{2}
$$

Our result implies $\frac{\partial \operatorname{Pr}(S E)}{\partial I_{d}} \gtreqless 0$, according to $S I_{d} \lesseqgtr \overline{S I_{d}}=\frac{\beta_{1}}{\beta_{2}}$. This means that greater informal networks positively affect the probability of starting a business as long as the quality of the formal court is below a certain threshold. However as the formal institutions become sufficiently strong, a higher number of business would quit in areas with larger informal networks.

Table 2 Probability of self employment vs wage employment

\begin{tabular}{|c|c|c|c|c|c|}
\hline & (1) & $(2)$ & (3) & (4) & (5) \\
\hline \multirow[t]{2}{*}{ IN*FC } & $-0.633^{* *}$ & $-0.675^{* * *}$ & $-0.792^{* * *}$ & $-0.667^{* *}$ & $-0.630^{* *}$ \\
\hline & $(0.249)$ & $(0.255)$ & $(0.290)$ & $(0.260)$ & $(0.268)$ \\
\hline \multirow[t]{2}{*}{ Informal Network(IN) } & $0.355^{* *}$ & $0.384^{* *}$ & $0.344^{* *}$ & $0.334^{* *}$ & $0.315^{*}$ \\
\hline & $(0.148)$ & $(0.152)$ & $(0.172)$ & $(0.156)$ & $(0.162)$ \\
\hline \multirow[t]{2}{*}{ Formal Court(FC) } & 0.031 & 0.043 & $0.095^{*}$ & 0.084 & 0.082 \\
\hline & $(0.035)$ & $(0.036)$ & $(0.053)$ & $(0.053)$ & $(0.053)$ \\
\hline \multirow[t]{2}{*}{ Formal Loan Availability } & & -0.083 & -0.072 & $-0.136^{*}$ & $-0.144^{* *}$ \\
\hline & & $(0.052)$ & $(0.067)$ & $(0.071)$ & $(0.07)$ \\
\hline \multirow[t]{2}{*}{ Loan Amount } & & & $0.001^{* *}$ & $0.001^{* *}$ & $0.001^{* *}$ \\
\hline & & & $(0.001)$ & $(0.001)$ & $(0.001)$ \\
\hline \multirow[t]{2}{*}{ Caste Association } & & & & & $0.027^{*}$ \\
\hline & & & & & $(0.014)$ \\
\hline \multirow[t]{2}{*}{ Hindu } & & & & $-0.079 * * *$ & $-0.079 * * *$ \\
\hline & & & & $(0.012)$ & $(0.012)$ \\
\hline \multirow[t]{2}{*}{ High Caste } & & & & $0.0671^{* *}$ & $0.069^{* * *}$ \\
\hline & & & & $(0.023)$ & $(0.023)$ \\
\hline \multirow[t]{2}{*}{ Education } & & & & $0.144^{* * *}$ & $0.144^{* * *}$ \\
\hline & & & & (0.009) & (0.009) \\
\hline \multirow[t]{2}{*}{ Constant } & $0.213^{* * *}$ & $0.218^{* * *}$ & $0.207^{* * *}$ & $0.170^{* * *}$ & $0.167^{* * *}$ \\
\hline & $(0.019)$ & $(0.019)$ & $(0.031)$ & $(0.033)$ & $(0.033)$ \\
\hline Observations & 34,521 & 34,521 & 14,185 & 14,159 & 14,156 \\
\hline R-squared & 0.001 & 0.002 & 0.007 & 0.033 & 0.034 \\
\hline
\end{tabular}

Source: IHDS 2004-2005, own calculations.

Notes: Linear probability models. Standard errors in parentheses, adjusted for clustering at village level.

*** significant at $1 \%$; ${ }^{* *}$ significant at $5 \%$; significant at $10 \%$. 
More specifically the coefficients can be interpreted in the following way. In column 1 , the estimates imply that the threshold level of formal institutions is given by $0.54\left(\beta_{2} / \beta_{1}\right)$. Hence, districts where more than $54 \%$ of the households perceive the judiciary to be strong are above the threshold level of formal institutions. Now consider two districts within this group - one with a low prevalence of informal networks $\left(D_{L I}\right)$ and another with a high prevalence of informal networks $\left(D_{H I}\right)$. Then our coefficients imply that the probability of self employment is lower in $D_{H I}$ compared to $D_{L I}{ }^{5}$ Specifically, if $60 \%$ of households perceive the court to be efficient, then a one unit difference in the extent of informal networks between $D_{H I}$ and $D_{L I}$ leads to a 10 percentage point lower probability of self employment in $D_{H I}$ compared to $D_{L I}$ districts.

Conversely, now consider the situation where the level of formal institutions is less than the threshold level of 0.5 . Consider the same two districts, $D_{H I}$ and $D_{L I}$. Here our coefficients imply that the the probability of self employment is higher in $D_{H I}$ compared to $D_{L I}$. Specifically, if only $40 \%$ of the households in a district perceive the court to be strong, a one unit higher level of informal networks leads to a 10 percentage point higher likelihood of doing business.

Next we add a number of control variables to the above basic specification. It is possible that districts with greater availability of informal loans also have a higher availability of any loan so that 'IN' simply captures the extent of the total loan availability in the district instead of the extent of informality. Hence, we control for the availability of formal loans in the district in column 2. The coefficients indicate similar effects of informality.

Column 3 includes a proxy for the credit worthiness of a household indicated by the maximum amount of loan taken. Results remain unchanged here as well. The coefficient on the control variable suggests the obvious that if a household has taken a larger amount of loan, it is more likely to start a business.

Column 4 controls for other household level characteristics like religion, caste and an indicator whether a household has any literate member. The results are in the same spirit as before. The coefficients on High Caste and Education are as expected. More educated households and traditionally higher castes are more likely to be self employed. Hindu households, on the contrary, are less likely to self employed compared to households from other religious backgrounds.

Finally, in column 5 we also control for household participation in a caste network since that might increase both a household's probability of getting a loan and starting a business. Results remain the same as before. Moreover, as expected, household participation in a caste network increases the probability of self-employment.

To further verify that our results are not sensitive to varied specifications, we carry out the following robustness check. In Table 3 we include unemployment in the reference category. We now compare the probability of self employment with wage employment and unemployment. The results remain unaffected by the inclusion of unemployment in the reference category. The coefficients on the interaction term and informal institutions show similar nonlinear effects of informal networks on business decision, depending on the extent of formal institutions.

\subsection{Heterogeneity analysis}

In Table 1 we observe that the incidence of self-employment is much higher in urban areas compared to rural areas. Hence, in Table 4, we estimate the relationship separately 
Table 3 Probability of self employment vs wage employment \& unemployment

\begin{tabular}{|c|c|c|c|c|c|}
\hline & (1) & $(2)$ & (3) & (4) & (5) \\
\hline \multirow[t]{2}{*}{$\mathrm{IN*FC}$} & $-0.596^{* *}$ & $-0.630 * * *$ & $-0.798^{* * *}$ & $-0.688^{* * *}$ & $-0.652^{* *}$ \\
\hline & $(0.230)$ & $(0.237)$ & $(0.275)$ & $(0.251)$ & $(0.260)$ \\
\hline \multirow[t]{2}{*}{ Informal Network(IN) } & $0.355^{* * *}$ & $0.379^{* * *}$ & $0.354^{* *}$ & $0.350^{* *}$ & $0.333^{* *}$ \\
\hline & $(0.137)$ & $(0.141)$ & $(0.164)$ & $(0.151)$ & $(0.157)$ \\
\hline \multirow[t]{2}{*}{ Formal Court(FC) } & 0.031 & 0.041 & $0.102^{*}$ & $0.092^{*}$ & $0.091^{*}$ \\
\hline & $(0.033)$ & $(0.035)$ & $(0.052)$ & $(0.051)$ & $(0.052)$ \\
\hline \multirow[t]{2}{*}{ Formal Loan Availability } & & -0.071 & -0.081 & $-0.143^{* *}$ & $-0.151^{* *}$ \\
\hline & & $(0.051)$ & $(0.066)$ & $(0.071)$ & $(0.069)$ \\
\hline \multirow[t]{2}{*}{ Loan Amount } & & & $0.001^{* *}$ & $0.001^{* * *}$ & $0.001^{* * *}$ \\
\hline & & & $(0.001)$ & $(0.001)$ & $(0.001)$ \\
\hline \multirow[t]{2}{*}{ Caste Association } & & & & & $0.028^{* *}$ \\
\hline & & & & & $(0.014)$ \\
\hline \multirow[t]{2}{*}{ Hindu } & & & & $-0.071^{* * *}$ & $-0.071^{* * *}$ \\
\hline & & & & $(0.012)$ & $(0.012)$ \\
\hline \multirow[t]{2}{*}{ High Caste } & & & & $0.059^{* * *}$ & $0.061^{* * *}$ \\
\hline & & & & $(0.022)$ & $(0.022)$ \\
\hline \multirow[t]{2}{*}{ Education } & & & & $0.139^{* * *}$ & $0.139 * * *$ \\
\hline & & & & $(0.009)$ & $(0.009)$ \\
\hline \multirow[t]{2}{*}{ Constant } & $0.196^{* * *}$ & $0.201^{* * *}$ & $0.195^{* * *}$ & $0.155^{* * *}$ & $0.152^{* * *}$ \\
\hline & $(0.018)$ & $(0.019)$ & $(0.031)$ & $(0.032)$ & $(0.033)$ \\
\hline Observations & 36,837 & 14,737 & 14,708 & 14,704 & \\
\hline R-squared & 0.002 & 0.007 & 0.031 & 0.031 & \\
\hline
\end{tabular}

Source: IHDS 2004-2005, own calculations.

Notes: Linear probability models. Standard errors in parentheses, adjusted for clustering at village level.

***significant at $1 \%$; ${ }^{* *}$ significant at $5 \%$; *significant at $10 \%$.

for rural and urban regions. ${ }^{6}$ The results discussed in Table 2 are primarily driven by the urban region. Informality by itself or its interaction with formal institutions doesn't play a significant role in predicting self employment for the rural region. It is possible that the link between informality and self employment is more relevant for the urban region which is characterized by a higher prevalence of self-employment.

In general, it should be easier to start a new business in the presence of a large informal network because it facilitates the flow of information and provides easy access to loans. However, according to our theoretical predictions, the presence of a large informal network would also lead to a greater exodus of businesses when the quality of formal institutions crosses a threshold. To re-examine these possibilities we conduct a heterogeneity analysis by estimating our model separately for the extent of association of households in various caste organizations. In districts where a large fraction of households participate in caste networks, there would be a greater flow of information within the network. Consequently, it would be easier to enforce contracts using the informal system of the reputation mechanism and facilitate business opportunities. We define a district to have a strong caste network if a larger share of households in a district participate in caste organizations. ${ }^{7}$ Table 5 reports the results from this analysis. A one percentage point increase in the size of informal networks leads to a 0.52 percentage point higher probability of doing business in districts with large caste networks. In comparison, a one percentage point increase in the size of informal networks leads to a 0.32 percentage point higher probability of doing business in districts with small caste networks. Additionally, the coefficient 


\begin{tabular}{lll}
\hline & $\mathbf{( 1 )}$ & $\mathbf{( 2 )}$ \\
\hline IN*C & Rural & Urban \\
& -0.339 & $-0.849^{* * *}$ \\
Informal Network(IN) & $(0.292)$ & $(0.300)$ \\
& 0.121 & $0.421^{* *}$ \\
Formal Court(FC) & $(0.184)$ & $(0.179)$ \\
& 0.056 & 0.128 \\
Formal Loan Availability & $(0.055)$ & $(0.084)$ \\
& $-0.173^{* *}$ & -0.072 \\
Loan Amount & $(0.067)$ & $(0.123)$ \\
Caste Association & $0.003^{* * *}$ & $0.001^{* * *}$ \\
Hindu & $(0.001)$ & $(0.001)$ \\
& 0.019 & $0.075^{* *}$ \\
High Caste & $(0.0139)$ & $(0.0292)$ \\
& $-0.085^{* * *}$ & $-0.04^{* *}$ \\
Education & $(0.016)$ & $(0.02)$ \\
Constant & $0.091^{* * *}$ & 0.02 \\
Observations & $(0.033)$ & $(0.034)$ \\
R-squared & $0.126^{* * *}$ & $0.130^{* * *}$ \\
Soure: & $(0.009)$ & $(0.022)$ \\
& $0.185^{* * *}$ & $0.161^{* * *}$ \\
& $(0.036)$ & $(0.051)$ \\
& 9,622 & 4,534 \\
& 0.037 & 0.017 \\
\hline
\end{tabular}

Source: IHDS 2004-2005, own calculations.

Notes: Linear probability models. Standard errors in parentheses, adjusted for clustering at village level.

**** significant at $1 \%$; ** significant at $5 \%$; ${ }^{*}$ significant at $10 \%$.

on the interaction term shows that the fall in business opportunities is higher in districts with large caste networks when the quality of the formal court is above a threshold.

Finally, we also investigate how a greater influx of $\mathrm{NC}$ entrepreneurs affects our baseline relationship. Specifically, we look at the extent of migration into and out of a district as it determines the composition of the pool of entrepreneurs within a district. A higher number of out-of-community entrepreneurs is likely to be present in high-migration compared to low-migration districts. ${ }^{8}$ Analogously, a higher number of low-endowment community entrepreneurs will operate in low migration districts. In this situation when the formal institutions become sufficiently strong, there would be a greater exit of low-endowment entrepreneurs from the low-migration districts. In other words, since high-migration districts would have a larger number of high-endowment out-of-community entrepreneurs to begin with, the interaction between informal network and formal courts will have a much weaker effect than the low-migration districts, which are populated by low-endowment entrepreneurs. Therefore, we conduct a heterogeneity analysis separately for districts with high and low migration in the urban region as presented in Table 6. We define a district to have high migration if the fraction of migrants in that district is greater than the median. In accordance with our theoretical predictions, the informal network and its interaction with the formal court matters for self-employment in districts with low-migration, possibly due to a greater prevalence of community entrepreneurs. We do not find any significant relationship for the districts with high-migration. 
Table 5 Heterogeneity analysis: network size

\begin{tabular}{lll}
\hline & $(\mathbf{1})$ & $(\mathbf{2})$ \\
\hline IN*C & Large Network & Small Network \\
& $-1.040^{* * *}$ & $-0.643^{* *}$ \\
Informal Network(IN) & $(0.376)$ & $(0.317)$ \\
Formal Court(FC) & $0.528^{* *}$ & $0.314^{*}$ \\
& $(0.218)$ & $(0.166)$ \\
Formal Loan Availability & $0.135^{*}$ & 0.105 \\
& $(0.078)$ & $(0.069)$ \\
Loan Amount & -0.029 & -0.138 \\
& $(0.091)$ & $(0.102)$ \\
Caste Association & $0.001^{*}$ & $0.001^{* *}$ \\
Hindu & $(0.000)$ & $(0.000)$ \\
High Caste & $0.052^{* *}$ & $0.158^{*}$ \\
& $(0.024)$ & $(0.092)$ \\
Education & $-0.041^{*}$ & $-0.045^{*}$ \\
Constant & $(0.024)$ & $(0.025)$ \\
R-squared & 0.057 & -0.008 \\
Soure: & $(0.042)$ & $(0.037)$ \\
& $0.129^{* * *}$ & $0.127^{* * *}$ \\
& $(0.032)$ & $(0.029)$ \\
& $0.164^{* * *}$ & $0.176^{* * *}$ \\
& $(0.056)$ & $(0.051)$ \\
& 2,323 & 2,211 \\
& 0.017 & 0.016 \\
\hline
\end{tabular}

Source: IHDS 2004-2005, own calculations.

Notes: Linear probability models. Standard errors in parentheses, adjusted for clustering at village level.

${ }^{* * *}$ significant at $1 \%$; ** significant at $5 \%$; ${ }^{*}$ significant at $10 \%$.

\section{Conclusion}

The relation between the informal and formal institutions of contract enforcement is usually seen as substitutional - the former being replaced by the latter in the course of economic development. The experiences of developing countries, however, show that these two type of institutions co-exist. Understanding the nature of their interaction therefore becomes crucial for designing optimal institutions. In this paper we model the interaction between these two types of institutions and its effect on the prospect of running a business. We test the implications of the model using household level data for India.

The informal institutions of contract enforcement, which works on a reputation based mechanism, are critical for the operations of micro-entrepreneurs who cannot access costly formal institutions for enforcing the contracts. Unlike the formal institutions which depend on the legal system for enforcing contracts, the informal institutions punish a cheater by denying him any future employment. However, such mechanisms are limited to certain communities where members abide by the community norm of not employing one who has cheated someone from that community. The system gets weaker if entrepreneurs start violating this norm. The rise of formal institutions allows non-community members to enter the market who do not follow such norms. This, in our analysis, significantly weakens the effectiveness of the informal institutions.

Our theoretical result shows that as long as the quality of formal institutions is below a threshold level, strong informal networks help in business proliferation. However, when the formal institutions get sufficiently strong, they come in the way of the informal ones 
Table 6 Heterogeneity analysis: migration

\begin{tabular}{lll}
\hline & $(\mathbf{1})$ & $(\mathbf{2})$ \\
\hline IN*FC & High Migration & Low Migration \\
& -0.701 & $-0.809^{* *}$ \\
Informal Network(IN) & $(0.647)$ & $(0.369)$ \\
Formal Court(FC) & 0.311 & $0.491^{*}$ \\
& $(0.318)$ & $(0.263)$ \\
Formal Loan Availability & 0.152 & 0.045 \\
Loan Amount & $(0.120)$ & $(0.108)$ \\
Caste Association & -0.085 & -0.002 \\
Hindu & $(0.169)$ & $(0.174)$ \\
& $0.001^{* * *}$ & $0.001^{* * *}$ \\
High Caste & $(0.000)$ & $(0.000)$ \\
& $0.078^{* *}$ & 0.072 \\
Education & $(0.037)$ & $(0.044)$ \\
Constant & $-0.049^{*}$ & -0.025 \\
Observations & $(0.026)$ & $(0.03)$ \\
R-squared & -0.002 & 0.053 \\
SourceIHDS & $(0.042)$ & $(0.06)$ \\
& $0.125^{* * *}$ & $0.141^{* * *}$ \\
& $(0.029)$ & $(0.036)$ \\
& $0.160^{* *}$ & $0.169^{* *}$ \\
& $(0.071)$ & $(0.078)$ \\
& 2,786 & 1,748 \\
& 0.017 & 0.023 \\
\hline
\end{tabular}

Source: IHDS 2004-2005, own calculations.

Notes: Linear probability models. Standard errors in parentheses, adjusted for clustering at village level.

${ }^{* * *}$ significant at $1 \%$; ${ }^{* *}$ significant at $5 \%$; ${ }^{*}$ significant at $10 \%$.

(following the mechanism we detailed above) and increase the cost of running businesses. This affects the poorer entrepreneurs more adversely than their more well off counterparts because it is the small capitalists who find running business using the formal mechanism not profitable enough. We test our theoretical predictions using IHDS data and find support for our theoretical results. We plan to extend our analysis in the future by constructing a panel using administrative data on court quality. Additionally, future waves of IHDS data would allow us to observe the evolution of informal institutions over time. This will help us to provide more convincing evidence.

The main result of our paper apparently warns against the possible backlash of strengthening the formal institutions in a less developed country that is characterized by strong informal institutions. Our position, however, does not endorse maintenance of informal mechanisms. Instead, we emphasize that informal institutions, even though inefficient, are crucial for the micro-entrepreneurs to run their businesses. The implications of our paper are two fold: first, strong formal and strong informal institutions create a negative impact on the probability of doing business; more importantly, such negative impacts typically force the capital poor section of the entrepreneurs to quit the market. Hence, even if the strengthening of formal institutions may lead to efficient outcomes in the long run, it increases inequality in the short run. The main contribution of our paper is to emphasizing this trade off which is often neglected in the institutions-entrepreneurship literature. The policy implication should lead to a better designing of formal institutions so that the exclusion of micro-entrepreneurs can be prevented. 


\section{Endnotes}

${ }^{1}$ One such study is done by Kranton and Swamy (1999) who conduct a descriptive analysis of the effect of court systems on agricultural credit markets using historical data from British India.

${ }^{2}$ We also define a separate category as agricultural household if at least one member owns agricultural land or is employed in agriculture and no one is self-employed or wage-employed. However, we did not include this reference category in our analysis because they form a very small fraction of the total number of households.

${ }^{3}$ All our district level estimates are computed as a fraction of the total number of households in a district.

${ }^{4}$ Note that the formal court quality measure might suffer from measurement error problems as it is based on household perception, implying that our estimates form a lower bound. We plan to collect administrative data related to court quality to construct a more precise measure.

${ }^{5}$ For $S I_{d}=0.6, P(S E)=\beta_{0}+\beta_{1} I I_{d} * 0.6+\beta_{2} I I_{d}$.

${ }^{6}$ These results are robust to all the specifications reported in Table 2. However, we only report the specification with full set of controls.

${ }^{7}$ Moreover since the baseline relationship is driven primarily by the urban sector, we restrict this analysis to the urban sector.

${ }^{8}$ Out-of-community entrepreneurs represent the NC entrepreneurs in our theoretical model.

\section{Appendix}

$$
\begin{aligned}
& V_{h}[1-\beta(1-q)]=\rho^{*}+q V_{h}^{u} \\
& V_{h}^{u}=\beta p_{h} V_{h}+\beta\left(1-p_{h}\right)\left(\bar{w}+V_{h}^{u}\right) \\
& V_{c}^{u}=\beta p_{c} V_{h}+\beta\left(1-p_{c}\right)\left(\bar{w}+V_{c}^{u}\right) \\
& V_{h} \geq \eta+V_{c}^{u}
\end{aligned}
$$

Define $T=\frac{1}{1-\beta(1-q)}$. So we have

$$
V_{h}=T \rho^{*}+T q V_{h}^{u}
$$

Substituting this in equation (8), we get

$$
\begin{aligned}
& V_{h}^{u}=\beta p_{h}\left[\rho^{*} T+T q V_{h}^{u}\right]+\beta\left(1-p_{h}\right) V_{h}^{u}+\beta\left(1-p_{h}\right) \bar{w} \\
& V_{h}^{u}\left[1-\beta p_{h} T q-\beta\left(1-p_{h}\right)\right]=\beta p_{h} \rho T+\beta\left(1-p_{h}\right) \bar{w}
\end{aligned}
$$

From the last equation, we get

$$
V_{h}^{u}=\frac{T \rho \beta p_{h}}{\left[1-\beta p_{h} T q-\beta\left(1-p_{h}\right)\right]}+\frac{\beta\left(1-p_{h}\right)}{\left[1-\beta p_{h} T q-\beta\left(1-p_{h}\right)\right]} \bar{w}
$$

We can then write the previous expression as

$$
V_{h}^{u}=\rho T_{1 h}+T_{2 h} \bar{w}
$$

From equation (9) we get

$$
V_{c}^{u}\left(1-\beta\left(1-p_{c}\right)\right)=\beta p_{c} V_{h}+\beta\left(1-p_{c}\right) \bar{w}
$$


The above expression can be written as

$$
V_{c}^{u}=T_{1 c} V_{h}+T_{2 c} \bar{w}
$$

where $T_{1 c}=\frac{\beta p_{c}}{1-\beta\left(1-p_{c}\right)}$ and $T_{2 c}=\frac{\beta\left(1-p_{c}\right.}{1-\beta\left(1-p_{c}\right)}$. The honesty-inducing condition tells us

$$
V_{h}-V_{c}^{u} \geq \eta
$$

Substituting from the previous expressions, we find

$$
V_{h}-\left(T_{1 c} V_{h}+T_{2 c} \bar{w}\right) \geq \eta
$$

From equations (11) and (15), we find

$$
T \rho^{*}+T q\left[\rho T_{1 h}+T_{2 h} \bar{w}\right] \geq \frac{\eta}{1-T_{1 c}}+\frac{T_{2 c}}{1-T_{1 c}} \bar{w}
$$

From this we get

$$
\rho T\left[1+T q T_{1 h}\right] \geq \frac{\eta}{1-T_{1 c}}+\frac{T_{2 c}}{1-T_{1 c}} \bar{w}-T q T_{2 h} \bar{w}
$$

This leads to the condition

$$
\rho \geq \frac{1}{T\left[1+T q T_{1 h}\right]} \times\left[\frac{\eta}{1-T_{1 c}}+\frac{T_{2 c}}{1-T_{1 c}} \bar{w}-T q T_{2 h} \bar{w}\right]
$$

Recall that

$$
\frac{1}{1-T_{1 c}}=1+\frac{\beta}{1-\beta} p_{c}
$$

and

$$
\frac{T_{2 c}}{1-T_{1 c}}=\frac{\beta\left(1-p_{c}\right)}{1-\beta}
$$

Hence, we find,

$$
\frac{\partial \rho^{*}}{\partial p_{c}}=\frac{1}{T\left[1+T q T_{1 h}\right]} \times(\eta-\bar{w}) \frac{\beta}{1-\beta}
$$

This expression is positive as long as $\eta-\bar{w}>0$, which tells us that the one time cheating payoff is more than the reservation payoff. This has to be the case because the industry payoff is more than the reservation wage, and the one time cheating payoff is more than the industry payoff.

\section{Competing interests}

The IZA Journal of Labor \& Development is committed to the IZA Guiding Principles of Research Integrity. The authors declare that they have observed these principles.

\section{Acknowledgements}

'We thank the seminar participants at Delhi School of Economics, IIT Kanpur, ISI-Calcutta, Indian School of Business, University of Hannover and conference participants at IZA/World Bank Conference on Employment and Development 2014 and CEA 2014 for their useful comments and suggestions. We are also thankful to an anonymous referee for the valuable feedback. We gratefully acknowledge the funding received from ICSSR and IDRC for this project.

Responsible editor: David Lam

\section{Author details}

${ }^{1}$ Indian Institute of Technology, Kanpur, India. ${ }^{2}$ University of Calcutta, Calcutta, India.

Received: 25 September 2014 Accepted: 4 March 2015

Published online: 26 May 2015

\section{References}

Acemoglu D, Johnson S (2003) Unbundling Institutions. Technical report, National Bureau of Economic Research Acemoglu D, Johnson S, Robinson J (2001) The colonial origins of comparative development. Am Econ Rev 91(5):1369-1401 
Acemoglu D, Johnson S, Robinson J (2002) Reversal of fortune:geography and institutions in the making of the modern world income distribution. Q J Econ 117(4):1231-1294

Besley T, Coate S, Loury G (1993) The economics of rotating savings and credit associations. Am Econ Rev 83(4):792-810 Biggs T, Shah MK (2006) African smes, networks, and manufacturing performance. J Bank Finance 30(11):3043-3066

Biggs RMT, Srivastava P (2002) Ethnic networks and access to credit: Evidence from the manufacturing sector in kenya. J Econ Behav Organ 49:473-486

Blanchflower DG, Levine PB, Zimmerman DJ (2003) Discrimination in the small-business credit market. Rev Economics Stat 85(4):930-943

Chowdhry P (2004) Caste panchayats and the policing of marriage in haryana: Enforcing kinship and territorial exogamy. Contrib Indian Sociol 38(1-2):1-42

Chemin M (2012) Does court speed shape economic activity? evidence from a court reform in india. J Law Economics and Organization 28(3):460-485

Dixit A (2004) Lawlessness and economics: alternative modes of governance. Princeton University Press

Fafchamps M (2000) Ethnicity and credit in african manufacturing. J Dev Economics 61(1):205-235

Fafchamps M (2003) Ethnicity and networks in african trade. Contrib Econ Anal Policy 2(1):14

Fairlie RW, Robb AM (2007) Why are black-owned businesses less successful than white-owned businesses? the role of families, inheritances, and business human capital. J Labor Econ 25(2):289-323

Fisman RJ (2003) Ethnic ties and the provision of credit: Relationship-level evidence from african firms. B.E. J Econ Anal Policy advances.3(1):4

Freitas K (2006) The indian caste system as a means of contract enforcement. Nortwestern University. unpublished manuscript

Gajigo O, Foltz JD (2010) Ethnic Networks and Enterprise Credit: The Serahules of The Gambia. Working Paper

Ghatak M (1991) Group lending, local information and peer selection. J Dev Econ 60(1):27-50

Ghosh P, Ray D (1996) Cooperation in community interaction without information flows. Rev Econ Stud 63(3):491-519

Greif A, Milgrom P, Weingast B (1994) Coordination, commitment, and enforcement: The case of the merchant guild. J Pol Econ 102(August):745-776

Greif A (1993) Contract enforceability and economic institutions in early trade: The maghribi traders' coalition. Am Econ Rev 83(3):525-548

Harriss-White B (2010) Globalization, the financial crisis and petty production in indias socially regulated informal economy. Glob Labour J 1(1):152-177

Kandori M (1992) Social norms and community enforcement. Rev Econ Stud 59(1):63-80

Karlan D (2005) Using experimental economics to measure social capital and predict financial decisions. Am Econ Rev 95(5):526-556

Keremane GB, McKay J, Narayanamoorthy A (2006) The decline of innovative local self-governance institutions for water management the case of pani panchayats. Int J Rural Manag 2(1):107-122

Klapper L, Laeven L, Rajan R (2006) Entry regulation as a barrier to entrepreneurship. J Financ Econ 82(3):591-629

Kranton RE, Swamy AV (1999) The hazards of piecemeal reform: British civil courts and the credit market in colonial india. J Dev Econ 58(1):1-24

La Porta R, Shleifer A (2014) Informality and development. J Econ Perspect 28(3):109-26

Luigi S, Sapienza P, Zingales L (2004) The role of social capital in financial development. Am Econ Rev 94(3):526-556

Madsen ST (1991) Clan, kinship, and panchayat justice among the jats of western uttar pradesh. Anthropos 86:351-365

McMillan J, Woodruff C (1999) Interfirm relationships and informal credit in vietnam. Q J Econ 114(4):1285-1320. doi:10.1162/003355399556278

Nagraj V (2010) Local and customary forums : Adapting and innovating rules of formal law. Indian J Gender Stud 17(3):429-450

Rajan R, Zingales L (1998) Financial dependence and growth. Am Econ Rev 88(5):559-586

Rosenthal R, Landau H (1979) A game theoretic analysis of bargaining with reputation. J Math Psychol 20:235-255

Sandner V (2003) Myths and laws: changing institutions of indigenous marine resource management in Central America. Springer

Shapiro C, Stiglitz JE (1984) Equilibrium unemployment as a worker discipline device. The American Economic Review

Slivinski A, Sussman N (2009) Taxation mechanisms and growth, in medieval paris. In: Geneva, European Economic History Association Conference

Straub S (2005) Informal sector: The credit market channel. J Dev Econ 78(2):299-32

Yadav B (2009) Khap panchayats: Stealing freedom? Econ Pol Wkly 44(52):16-19 